\title{
Prevalence of and factors associated with various level of body weight among Inner Mongolia medical students in China
}

\author{
Jiang Bian ${ }^{1}$, He $\mathrm{Yi}^{1}$, Zhiyue Liu ${ }^{1}$, Gaimei $\mathrm{Li}^{2}$, Teer Ba ${ }^{1}$, Qing Zhang ${ }^{1}$, Juan Sun ${ }^{1^{\star}}$ \\ ${ }^{1}$ Inner Mongolia Medical College, Hohhot, China; ${ }^{*}$ Corresponding Author: cnsunjuan@yahoo.com.cn \\ ${ }^{2}$ Institute of Media, Inner Mongolia Normal University, Hohhot, China
}

Received 20 January 2012; revised 28 February 2012; accepted 23 March 2012

\section{ABSTRACT}

Background: To date no study on the body weight of medical students in Inner Mongolia has been carried out. The aim of the present study was to determine the prevalence of and factors associated with various body weight levels, and the physical health status associated with body weight levels among medical students attending the Inner Mongolia Medical College of China in 2011. Methods: Data on participant characteristics came from basic information contained in the school database. Students' body weight was categorized using standard height and weight and physical health status using the college student physical health standard. Factors associated with various level of body weight were identified using multinomial logistic regression analysis. Results: The sample comprised 2060 males and 5096 females. The appropriate body weight prevalence among the students was $51.7 \%$. The prevalence of being overweight or obese was $5.8 \%$ and $8.5 \%$, respecttively, higher compared to the typical prevalence among college students in China. Both male and female students in the 24 - 28-years age group had the lowest appropriate weight percentage and the highest obesity percentage among all the age groups. For female medical students, the prevalence of obesity for students studying in Clinical Medicine was higher than for other faculties. Multinomial logistic regression analysis of male students showed that lowest year of education (year 1) was a protective factor in regard to appropriate weight. For both male and female medical students, the obese group had the highest proportion of poor physical health status compared to other categories of body weight and the proportion with excellent physiccal health status constituted $<1 \%$ for males and $0 \%$ for females. Conclusions: School administrators should encourage medical students to actively participate in body weight training and education to improve attitudes toward inappropriate body weight, to increase protective factors, and reduce the risk factors for inappropriate body weight.

Keywords: Body Weight; Physical Health; Medical Students; Prevalence

\section{INTRODUCTION}

The World Health Organization (WHO) has recommended that classifications of body weight include degrees of underweight and gradations of excess weight or overweight that are associated with increased risk of some non-communicable diseases [1,2]. This is because maintenance of appropriate body weight is a major determinant in the survival of higher organisms, including mammals [3], and several factors, including diet, genetic predisposition, physical activities, physiological and behavioral factors have been implicated [3,4]. Body weightrelated disorders are also a growing phenomenon in both developing and developed countries [5] with approximately 1.2 billion people in the world overweight and at least 300 million obese. Obesity is also one of the 10 most preventable health risks according to the WHO. Much has been written about the obesity epidemic [6] but malnutrition in children and adolescents also poses a considerably larger public health problem internationally $[7,8]$.

The WHO has taken the position that health personnel are important health promoters and role models for maintaining a healthy lifestyle in regard to the general population [9]. That health professionals' own health and health habits may influence their attitudes toward relevant professional behaviors has been demonstrated by studies of health professionals' weight status [10]. Moreover, studies of medical students and health personnel in 
many countries suggest that body weight-related disorders such as obesity are a problem among these population groups $[11,12]$. More importantly, physicians are expected to play an important role in the healthy lifestyle, which means not only giving advice to their patients but setting a good example for them. Consequently, as medical students become future health personnel, it is also important to measure their body weight to determine if this is a problem.

Inner Mongolia is a region inhabited by the Mongolian ethnic minority (one of five ethnic minorities within the autonomous region of China). Until now, in Inner Mongolia, no study has been conducted on body weight regarding medical students. Consequently, we decided to carry out an investigation among medical students of the Inner Mongolia Medical College with the aim of documenting the percentage of students in various body weight categories. In addition, our intent was to determine what factors are related to these categories. It was hoped that assessing students' body weight status would help health educators to develop proper education programs that promote a healthy lifestyle.

\section{MATERIALS AND METHODS}

\subsection{Setting and Target Population}

The study was carried out among medical students at the Inner Mongolia Medical College of China in 2011. Students belonged to the faculties of Clinical Medical, Public Health Administration, Medicine Information Management, Medicine, Traditional Chinese Medicine, Mongolian Medicine, Nurse, and others. We surveyed students in years $1-3$ of their education. A total of 7156 students were enrolled in the study.

\subsection{Measurement and Data Sources}

Students' weight levels were classified according to "national student standard height and weight" [13]. "Standard height and weight" (SHW) is the ratio between the height and weight in the normal range and is expressed in tabular form by gender. Chinese SHW indicators reflect the relationship between adult weight and height, evaluate the nutrition situation, and determine the degree of body mass $[13,14]$. The classification includes five levels: overweight, obese, underweight, malnutrition, and appropriate weight. When the students' height and body weight be known, we could look-up table of National Student SHW to determine their body weight level (Table 1).

We categorized students' physical health status according to the "college student physical health standard", which is one part of the "national student physical health standard" [15], and was established by Ministry of Education of China and the General Administration of Sport of China. It is the standard by which a Chinese college student's physical health is evaluated and includes items as vital capacity index, sidestep test, standing long jump, grip index, 1000-meter race, and 50-meters sprint. The total score of all test items is 100 points. After college students complete all test items, then score for the test items is calculated. The interpretation of the score is: poor ( $\leq 59$ points), normal ( $60-75$ points), good (76 - 85 points), and excellent ( $\geq 86$ points).

Relevant participant information was extracted from the basic information contained in the school database. Data on students' physical health status came from the Sports Departmentt of the Inner Mongolia Medicine College.

\subsection{Statistical Analysis}

We determined levels of body weight stratified by gender in relation to various items, including ethnicity, year of education, age, and faculty assignment. Multinomial logistic regression analysis was used to ascertain factors associated with various levels of body weight. This technique is used for analyses with dependent variables in three or more categories (in this case three categories: overweight and obese, underweight and malnutrition, and normal body weight, which is the reference group). Independent variables included in the model were eth-

Table 1. Categories of body weights for Chinese college students and Inner Mongolia medical students. Body weight categories for Chinese college students are taken from reference [16].

\begin{tabular}{lccccc}
\hline & Overweight (\%) & Obese (\%) & Underweight (\%) & Malnutrition (\%) & $\begin{array}{c}\text { Appropriate } \\
\text { Weight (\%) }\end{array}$ \\
\hline Chinese college students & 4.1 & 7.3 & 45.5 & 7.9 & 35.2 \\
Inner Mongolia medical students & 5.9 & 8.5 & 31.7 & 2.2 & 51.7 \\
Chinese male college students & 4.0 & 8.7 & 48.9 & 9.1 & 2.5 \\
Inner Mongolia male medical students & 9.7 & 19.7 & 24.4 & 6.5 & 43.8 \\
Chinese female college students & 4.3 & 5.9 & 46.2 & 34.7 & 2.1 \\
Inner Mongolia female medical students & 4.3 & 4.0 & & 54.9 \\
\hline
\end{tabular}


nicity (other ethnicity was the reference group), year of education (year 3 was the reference group), faculty (other faculty was the reference group), and age of student (24 28 years was the reference group). We used multinomial logistic regression models to adjust for possible confounding influences between the independent variables on the dependent variable in each model. In all models, odds ratios (ORs) $>1.0$ designated increased risk and ORs $<1.0$ indicated protective factors.

All statistical analyses were performed using SPSS for Windows v13.0, with a significance level of $\mathrm{P}<0.05$.

\subsection{Ethical Approval}

Ethical approval to conduct the study was obtained from the Ethical Committee of Inner Mongolia.

\section{RESULTS}

\subsection{Sample Characteristics}

The study included 2060 males and 5096 females. By gender, the prevalence of obesity among males was significantly higher than among female medical students $(19.7 \%$ vs. $4.0 \%)$ and nearly two times higher among male students compared to female students for being overweight [16].

Male students belonging to the other ethnicity had the lowest prevalence of malnutrition - not more than 1\%significantly lower than Han and Mongolian ethnicities (Table 2). The age group of $24-28$ years had the lowest prevalence of appropriate weight and the highest obesity prevalence among all age groups. Male students in the

Table 2. Male medical student characteristics for various levels of body weight.

\begin{tabular}{|c|c|c|c|c|c|}
\hline Characteristic & Overweight (\%) & Obese $(\%)$ & $\begin{array}{c}\text { Underweight } \\
(\%)\end{array}$ & $\begin{array}{c}\text { Malnutrition } \\
(\%)\end{array}$ & $\begin{array}{l}\text { Appropriate } \\
\text { Weight (\%) }\end{array}$ \\
\hline $\mathrm{n}$ & 199 & 405 & 502 & 51 & 903 \\
\hline \multicolumn{6}{|l|}{ Ethnicity } \\
\hline Han & 9.2 & 19.8 & 24.6 & 2.5 & 44.0 \\
\hline Mongolian & 10.7 & 19.8 & 24.0 & 2.9 & 42.5 \\
\hline Other & 11.4 & 17.1 & 23.6 & 0.8 & 47.2 \\
\hline \multicolumn{6}{|l|}{ Year of study } \\
\hline 1 & 9.1 & 17.0 & 25.9 & 2.4 & 45.6 \\
\hline 2 & 9.4 & 21.6 & 23.1 & 1.8 & 44.1 \\
\hline 3 & 10.7 & 20.3 & 24.2 & 3.5 & 41.3 \\
\hline \multicolumn{6}{|l|}{ Faculty } \\
\hline Clinical Medicine & 10.9 & 20.6 & 22.0 & 2.1 & 44.5 \\
\hline Traditional Chinese Mongolian Medicine & 7.9 & 19.5 & 27.0 & 2.8 & 42.8 \\
\hline Medicine & 10.2 & 20.5 & 24.2 & 2.3 & 42.8 \\
\hline Nurse & 3.9 & 11.8 & 33.3 & 2.0 & 49.0 \\
\hline Public Health Administration/Medicine Information & 12.1 & 15.6 & 26.3 & 2.2 & 43.8 \\
\hline \multicolumn{6}{|l|}{ Management } \\
\hline Other & 6.0 & 22.2 & 24.0 & 4.2 & 43.7 \\
\hline \multicolumn{6}{|l|}{ Age } \\
\hline 19 & 8.8 & 16.6 & 31.5 & 3.3 & 39.8 \\
\hline 20 & 9.7 & 19.7 & 24.8 & 1.6 & 44.2 \\
\hline 21 & 9.6 & 20.1 & 24.3 & 2.6 & 43.5 \\
\hline 22 & 10.6 & 18.7 & 22.6 & 3.0 & 45.0 \\
\hline 23 & 7.8 & 21.7 & 20.7 & 3.2 & 46.5 \\
\hline $24-28$ & 12.7 & 23.8 & 25.4 & 0.0 & 38.1 \\
\hline
\end{tabular}


faculty of Nurse had the lowest prevalence of being overweight (3.9\%), obesity (11.8\%), and malnutrition $(2.0 \%)$ as well as the highest prevalence of appropriate weight $(49.0 \%)$.

Female students of Mongolian ethnicity had the lowest prevalence of malnutrition (1.8\%) compared with Han $(2.1 \%)$ and other ethnicities (3.3\%) (Table 3). However, female students in year 3 of education had nearly 2.5 times the prevalence of malnutrition $(3.2 \%)$ compared to students in year 1 of education $(1.4 \%)$, and female students in the faculty of Clinical Medicine had the highest prevalence of obesity $(4.8 \%)$ and the lowest prevalence of being underweight (32.1\%) and malnutrition (1.4\%) compared with the other five faculties. Compared with the age group of $24-28$ years, all the other age groups had a prevalence of more than $50 \%$ for appropriate weight and less than $5 \%$ for obesity, while in the age group of 24 - 28 years, the highest prevalence for being overweight (5.0\%), obese $(6.3 \%$, ) and underweight (48.8\%) was observed, as well as the lowest prevalence for having appropriate weight $(38.8 \%)$.

\subsection{Factors Associated with Various Body Weight Level}

For male students, ethnicity was not a significant factor in the full multinomial logistic regression model (Table 4). In addition, students in the lowest year of education (year 1) were less likely have inappropriate body weight compared with students in higher years of education. For female students, Han and Mongolian ethnicities were significant protective factors for being underweight or having malnutrition compared with the category of other ethnicity (Table 5). Students in the faculty of Clinical Medicine were also less likely to be underweight or have malnutrition compared with other faculties.

Table 3. Female medical student characteristics for various levels of body weight.

\begin{tabular}{|c|c|c|c|c|c|}
\hline Characteristic & Overweight (\%) & Obese (\%) & $\begin{array}{c}\text { Underweight } \\
(\%)\end{array}$ & $\begin{array}{c}\text { Malnutrition } \\
(\%)\end{array}$ & $\begin{array}{l}\text { Appropriate } \\
\text { Weight (\%) }\end{array}$ \\
\hline $\mathrm{n}$ & 205 & 220 & 2799 & 1766 & 106 \\
\hline \multicolumn{6}{|l|}{ Ethnicity } \\
\hline Han & 4.5 & 3.8 & 35.0 & 2.1 & 54.6 \\
\hline Mongolian & 4.2 & 4.3 & 32.5 & 1.8 & 57.3 \\
\hline Other & 2.5 & 5.7 & 40.2 & 3.3 & 48.4 \\
\hline \multicolumn{6}{|l|}{ Year of study } \\
\hline 1 & 4.8 & 4.2 & 33.0 & 1.4 & 56.7 \\
\hline 2 & 4.4 & 3.8 & 36.1 & 2.2 & 53.5 \\
\hline 3 & 3.3 & 4.1 & 35.3 & 3.2 & 54.1 \\
\hline \multicolumn{6}{|l|}{ Faculty } \\
\hline Clinical Medicine & 4.3 & 4.8 & 32.1 & 1.4 & 57.4 \\
\hline Traditional Chinese Mongolian Medicine & 4.0 & 3.6 & 33.5 & 1.9 & 57.0 \\
\hline Medicine & 3.5 & 2.8 & 35.6 & 2.5 & 55.6 \\
\hline Nurse & 4.3 & 3.3 & 36.8 & 2.5 & 53.1 \\
\hline Public Health Administration/Medicine Information & 5.5 & 3.7 & 38.0 & 2.9 & 50.0 \\
\hline \multicolumn{6}{|l|}{ Management } \\
\hline Other & 4.5 & 4.6 & 36.3 & 2.4 & 52.2 \\
\hline \multicolumn{6}{|l|}{ Age } \\
\hline 19 & 5.0 & 3.6 & 33.9 & 1.3 & 56.3 \\
\hline 20 & 4.5 & 4.8 & 32.7 & 1.6 & 56.4 \\
\hline 21 & 4.3 & 3.5 & 34.3 & 2.3 & 55.6 \\
\hline 22 & 4.0 & 3.7 & 37.6 & 3.1 & 51.7 \\
\hline 23 & 3.0 & 3.7 & 35.8 & 2.5 & 55.0 \\
\hline $24-28$ & 5.0 & 6.3 & 48.8 & 1.3 & 38.8 \\
\hline
\end{tabular}


Table 4. Odds ratios (95\% CI) from multinomial logistic regressions comparing appropriate weight, overweight and obese, underweight and malnutrition on study measures for male medical students $(n=2060)$.

\begin{tabular}{|c|c|c|c|c|}
\hline \multirow{2}{*}{ Characteristic } & \multicolumn{2}{|c|}{ Overweight or Obese } & \multicolumn{2}{|c|}{ Underweight or Malnutrition } \\
\hline & OR & $95 \% \mathrm{CI}$ & OR & $95 \% \mathrm{CI}$ \\
\hline \multicolumn{5}{|l|}{ Ethnicity } \\
\hline Han & 1.11 & $0.72-1.73$ & 1.17 & $0.74-1.86$ \\
\hline Mongolian & 1.23 & $0.76-1.98$ & 1.16 & $0.71-1.92$ \\
\hline Other & - & - & - & - \\
\hline \multicolumn{5}{|l|}{ Year of education } \\
\hline 1 & 0.62 & $0.42-0.91^{*}$ & 0.60 & $0.40-0.89 *$ \\
\hline 2 & 0.84 & $0.61-1.16$ & 0.67 & $0.48-0.93^{*}$ \\
\hline 3 & - & - & - & - \\
\hline \multicolumn{5}{|l|}{ Faculty } \\
\hline Clinical Medicine & 0.98 & $0.65-1.48$ & 0.79 & $0.52-1.20$ \\
\hline Traditional Chinese Mongolian Medicine & 0.89 & $0.57-1.38$ & 1.03 & $0.67-1.60$ \\
\hline Medicine & 0.99 & $0.61-1.60$ & 0.93 & $0.57-1.51$ \\
\hline Nurse & 0.48 & $0.20-1.17$ & 1.11 & $0.55-2.28$ \\
\hline Public Health Administration/Medicine & 0.87 & $0.57-1.23$ & 0.98 & $0.60-1.62$ \\
\hline \multicolumn{5}{|l|}{ Information Management } \\
\hline Other & - & - & - & - \\
\hline \multicolumn{5}{|l|}{ Age (years) } \\
\hline 19 & 1.04 & $0.48-2.24$ & 2.04 & $0.91-4.57$ \\
\hline 20 & 0.97 & $0.50-1.91$ & 1.36 & $0.65-2.83$ \\
\hline 21 & 0.87 & $0.46-1.66$ & 1.26 & $0.62-2.54$ \\
\hline 22 & 0.74 & $0.40-1.38$ & 0.94 & $0.48-1.86$ \\
\hline 23 & 0.69 & $0.36-1.32$ & 0.79 & $0.39-1.62$ \\
\hline $24-28$ & - & - & - & - \\
\hline
\end{tabular}

${ }^{*} \mathrm{P}<0.05$; OR: odds ratio; CI: confidence interval.

There was also a significant increase in risk for being underweight or having malnutrition risk in the eldest age group compared with other lower age groups.

\subsection{Physical Health Status among Various Body Weight Level}

Male obese students had the highest prevalence for poor physical health status and lowest prevalence for excellent physical health status (Table 6) whereas students with an appropriate weight had the highest prevalence of being in the good and excellent categories of physical health status. Similar results were obtained with female obese students having a poor physical health status; there were no female students in the excellent category (Table 7). Moreover there were no female students in the category of excellent physical health status too for those classified as having malnutrition. Finally, female students in the appropriate weight category had the highest prevalence of good and excellent regarding physical health status.

\section{DISCUSSION}

Our study shows that the prevalence of appropriate weight among Inner Mongolia medical students is $51.7 \%$. This is considerably higher compared to the recently reported prevalence among Chinese college students in general (35.2\%) [16], but considerably lower compared to college students in other countries, such as Lebanon (64.7\%) [17], and Malaysia (68.8\%) [18]. Of particular note, in male students the prevalence of obesity and overweight is more than twice as high compared with male college students in China (19.7\% and 9.7\% vs $8.7 \%$ 
Table 5. Odds ratios $(95 \% \mathrm{CI})$ from multinomial logistic regressions comparing appropriate weight, overweight and obese, underweight and malnutrition on study measures for female medical students $(\mathrm{n}=5096)$.

\begin{tabular}{|c|c|c|c|c|}
\hline \multirow{2}{*}{ Characteristic } & \multicolumn{2}{|c|}{ Overweight or Obese } & \multicolumn{2}{|c|}{ Underweight or Malnutrition } \\
\hline & OR & $95 \% \mathrm{CI}$ & OR & $95 \% \mathrm{CI}$ \\
\hline \multicolumn{5}{|l|}{ Ethnicity } \\
\hline Han & 0.91 & $0.55-1.48$ & 0.74 & $0.57-0.98^{*}$ \\
\hline Mongolian & 0.91 & $0.54-1.54$ & 0.68 & $0.50-0.91^{*}$ \\
\hline Other & - & - & - & - \\
\hline \multicolumn{5}{|l|}{ Year of education } \\
\hline 1 & 1.10 & $0.73-1.66$ & 0.93 & $0.74-1.18$ \\
\hline 2 & 1.10 & $0.77-1.56$ & 1.08 & $0.89-1.31$ \\
\hline 3 & - & - & - & - \\
\hline \multicolumn{5}{|l|}{ Faculty } \\
\hline Clinical Medicine & 0.95 & $0.70-1.28$ & 0.75 & $0.63-0.90^{*}$ \\
\hline Traditional Chinese Mongolian Medicine & 0.80 & $0.55-1.15$ & 0.83 & $0.67-1.02$ \\
\hline Medicine & 0.69 & $0.45-1.06$ & 0.86 & $0.68-1.08$ \\
\hline Nurse & 0.84 & $0.57-1.23$ & 0.97 & $0.79-1.21$ \\
\hline Public Health Administration/Medicine & 1.09 & $0.73-1.63$ & 1.01 & $0.80-0.29$ \\
\hline \multicolumn{5}{|l|}{ Information Management } \\
\hline Other & - & - & - & - \\
\hline \multicolumn{5}{|l|}{ Age (years) } \\
\hline 19 & 0.49 & $0.21-1.16$ & 0.51 & $0.30-0.87^{*}$ \\
\hline 20 & 0.54 & $0.24-1.20$ & 0.47 & $0.29-0.78^{*}$ \\
\hline 21 & 0.46 & $0.21-1.02$ & 0.49 & $0.30-0.80^{*}$ \\
\hline 22 & 0.52 & $0.24-1.13$ & 0.61 & $0.37-0.99^{*}$ \\
\hline 23 & 0.44 & $0.19-1.02$ & 0.56 & $0.33-0.94^{*}$ \\
\hline $24-28$ & - & - & - & - \\
\hline
\end{tabular}

Table 6. Male medical student physical health status for various body weight levels.

\begin{tabular}{ccccc}
\hline \multirow{2}{*}{$\begin{array}{c}\text { Body Weight } \\
\text { Level }\end{array}$} & $\begin{array}{c}\text { Poor (\%) } \\
\mathrm{n}=444\end{array}$ & $\begin{array}{c}\text { Normal (\%) } \\
\mathrm{n}=816\end{array}$ & $\begin{array}{c}\text { Good (\%) } \\
\mathrm{n}=707\end{array}$ & $\begin{array}{c}\text { Excellent } \\
(\%) \mathrm{n}=93\end{array}$ \\
\cline { 2 - 5 } Overweight & 21.6 & 46.7 & 29.2 & 2.5 \\
Obese & 44.4 & 44.2 & 10.4 & 1.0 \\
Underweight & 18.9 & 48.2 & 31.5 & 1.4 \\
$\begin{array}{c}\text { Malnutrition } \\
\text { Appropriate } \\
\text { weight }\end{array}$ & 11.8 & 64.7 & 21.6 & 2.0 \\
Total & 13.3 & 29.8 & 48.5 & 8.4 \\
\hline
\end{tabular}

Table 7. Female medical student physical health status for various body weight levels.

\begin{tabular}{ccccc}
\hline \multirow{2}{*}{$\begin{array}{c}\text { Body Weight } \\
\text { Level }\end{array}$} & \multicolumn{4}{c}{ Physical health status } \\
\cline { 2 - 5 } & $\begin{array}{c}\text { Poor (\%) } \\
\mathrm{n}=444\end{array}$ & $\begin{array}{c}\text { Normal (\%) } \\
\mathrm{n}=816\end{array}$ & $\begin{array}{c}\text { Good (\%) } \\
\mathrm{n}=707\end{array}$ & $\begin{array}{c}\text { Excellent } \\
(\%) \mathrm{n}=93\end{array}$ \\
\hline Overweight & 21.4 & 56.4 & 21.8 & 0.5 \\
Obese & 34.6 & 51.7 & 13.7 & 0.0 \\
Underweight & 9.7 & 41.2 & 47.3 & 1.8 \\
Malnutrition & 10.4 & 47.2 & 42.5 & 0.0 \\
$\begin{array}{c}\text { Appropriate } \\
\text { weight }\end{array}$ & 8.2 & 31.3 & 56.4 & 4.1 \\
Total & 10.4 & 37.0 & 49.7 & 2.9 \\
\hline
\end{tabular}


and $4.0 \%$ ), respectively. In addition, the prevalence of these two body mass index conditions was more common among male compared to female students $(9.7 \%$ and $19.7 \%$ vs. $4.3 \%$ and $4.0 \%$, respectively).

While the prevalence of overweight and obesity categories for Inner Mongolia medical students represents a serious situation compared with Chinese college students in general, despite different definitions, these values are lower reported in the literature. For example, while the prevalence of being overweight or obese is $5.9 \%$ and $8.5 \%$ respectively in our study, in a survey conducted in the US during $2008,37.2 \%$ of adults were overweight and $22.4 \%$ obese [19]. A recent national study in Malaysia showed that the prevalence of obesity among adults was $11.7 \%$ [20], while among Greek medical students the prevalence of being overweight was $27.6 \%$ [12], and in a sample of 154 medical students in South Africa the rates for being overweight were $8.9 \%$ and $19.7 \%$ for Indian and black students, respectively [21].

Several findings in current study can be used to inform the development of effective health promotion programs among medical college students. First, for both male and female students, the highest age group had the lowest appropriate weight prevalence as well as the highest obesity prevalence. Consequently, while older students may represent the focal point for health researchers and health educators, it may be that the youngest groups ought to receive the most attention in terms of preventive education. Second, for male medical students, the prevalence of malnutrition among Han and Mongolian ethnicities was 3 and 3.5 times higher compared with the other ethnicity, respectively. This suggests that malnutrition prevention programs are important to maintain low malnutrition rates among other ethnicity, and that the focus should center on students of Han and Mongolian ethnicities to reduce the prevalence of malnutrition. Interestingly, we did not find that the prevalence of the various levels of body weight among Han and Mongolian ethnic groups was significantly different even though Inner Mongolia is considered one of China's five minority areas. We speculate that this result could be because Han and Mongolian ethnic groups have resided in the area a long time. Third, for female medical students, the prevalence of obesity for students studying in Clinical Medicine was higher than for other faculties while the prevalence for being underweight was lower. One possibility that might explain the results is that students in this faculty have heavier academic pressure, which caused their irregular eating habits. Many studies have shown that people who have irregular diet habits are more likely to be overweight or obese [17,22,23].

As with the findings of previous studies for Chinese college students, the multinomial logistic regression demonstrated that for male students a lower year of educa- tion was a protective factor in regard to appropriate weight [24-26]. For female students, it was the eldest group that was most likely to be underweight or have poor nutrition compared with other age groups. Possible reasons for these findings, which have been drawn from other Chinese studies, include a rapid acceleration of physical growth and development of students, the extended physical growing period, and relatively backward nutritional status compared with other students [27,28].

Another facet of our work indicated that for male medical students, nearly half of the students in the obese category had a poor physical health status (the highest percentage compared with other levels of body weight) with less than $1 \%$ having excellent physical health status. The situation for females was similar with nearly $35 \%$ of the obese students having a poor physical health status and none having excellent status. In contrast, there were fewer students who were underweight or had malnutrition and who also had a poor physical health status.

The present study had some limitations. Inappropriate body weight status was not assessed on the basis of self-reported data, which might have included questions about dietary habits or attitudes toward inappropriate body weight.

In conclusion, because medical students have medical knowledge and thus some understanding of the health hazards of inappropriate body weight, they might have an important role to play in programs that address inappropriate body weight. Such programs could involve medical students being given effective measures to change their attitudes regarding inappropriate body weight rather than emphasizing the harmful health effects of inappropriate body weight. In addition, school administrators should encourage students to actively participate in body weight training and education to improve attitudes toward inappropriate body weight, to increase protective factors, and reduce the risk factors for inappropriate body weight.

\section{REFERENCES}

[1] WHO (1995) Physical status: The use and interpretation of anthropometry. Report of a WHO Expert Consultation, WHO Technical Report Series, No. 854, Geneva.

[2] WHO (2000) Obesity: Preventing and managing the global epidemic. Report on a WHO Consultation on Obesity, Technical Report Series, No. 894, Geneva.

[3] Jequier, E. and Tappy, L. (1999) Regulation of body weight in humans. Physiological Reviews, 79, 451-480.

[4] Wilborn, C., Beckham, J., Campbell, B., Harvey, T., Melyn Galbreath, Bounty, P.L., Nassar, E., Wismann, J. and Kreider, R. (2005) Obesity: Prevalence, theories, medical consequences, management, and research directions. Journal of the International Society of Sports Nutrition, 2, 431. doi:10.1186/1550-2783-2-2-4 
[5] Jensen, M.K., Chiuve, S.E., Rimm, E.B., Dethlefsen, C., Tjønneland, A., Joensen, A.M. and Overvad, K. (2008) Obesity, behavioral lifestyle factors, and risk of acute coronary events. Circulation, 117, 3062-3069. doi:10.1161/CIRCULATIONAHA.107.759951

[6] Lobstein, T., Baur, L. and Uauy, R. (2004) Obesity in children and young people: A crisis in public health. Obesity Reviews, 5, 4-85. doi:10.1111/j.1467-789X.2004.00133.x

[7] Pelletier, D.L. and Frongillo, E.A. (2003) Changes in child survival are strongly associated with changes in malnutrition in developing countries. Journal of Nutrition, 133, 107-119.

[8] El-Ghannam, A.R. (2003) The global problems of child malnutrition and mortality in different world regions. Journal of Health \& Social Policy, 16, 1-26. doi:10.1300/J045v16n04_01

[9] WHO (1999) Leave the pack behind. World Health Organization, Geneva, 33-39.

[10] Zhu, D., Norman, I.J. and While, A.E. (2011) The relationship between health professionals' weight status and attitudes towards weight management: A systematic review. Obesity Reviews, 12, e324-e337.

[11] Abbate, C., Giorgianni, C., Munaò, F., Beninato, G., D'Arrigo, G., D'Arrigo, P. and Brecciaroli, R. (2006) Evaluation of obesity in healthcare workers. La Medicine del Lavoro, 97, 13-19.

[12] Bertsias, G., Mammas, I., Linardakis, M. and Kafatos, A. (2003) Overweight and obesity in relation to cardiovascular disease risk factors among medical students in Crete, Greece. BMC Public Health, 3, 3. doi:10.1186/1471-2458-3-3

[13] Ministry of Education of China and General Administration of Sport of China (2008) National student body hight standard and body weight index, Beijing.

[14] WHO Expert Consultation (2004) Appropriate body-mass index for Asian populations and its implications for policy and intervention strategies. Lancet, 363, 157-163.

[15] Ministry of Education of China and General Administration of Sport of China. (2008) College student physical health standard, Beijing.

[16] The Research Group of Physical Fitness and Health in Chinese Students. (2007) Report on the physical fitness and health surveillance of Chinese school students. Higher Education Press, Beijing.

[17] Yahia, N., Achkar, A., Abdallah, A. and Rizk, S. (2008) Eating habits and obesity among Lebanese University students. Nutrition Journal, 7, 6. doi:10.1186/1475-2891-7-32
[18] Boo, N.Y., Chia, G.J.Q., Wong, L.C., Chew, R.M., Chong, W. and Loo, R.C.N. (2010) The prevalence of obesity among clinical students in a Malaysian medical school. Singapore Medical Journal, 51, 126-132.

[19] Puhl, R., Andreyeva, T. and Brownell, K. (2008) Perceptions of weight discrimination: Prevalence and comparison to race and gender discrimination in America. International Journal of Obesity, 32, 992-1000.

[20] Rampal, L., Rampal, S., Khor, G., Azhar, M., Shafie, O., Ramlee, R., Sirajoon, N. and Jayanthi, K. (2007) A national study on the prevalence of obesity among 16,127 Malaysians. Asia Pacific Journal of Clinical Nutrition, 16, 561-566.

[21] Morar, N., Seedat, Y.K., Naidoo, D.P. and Desai, D.K. (1998) Ambulatory blood pressure and risk factors for coronary heart disease in black and Indian medical students. European Journal of Cardiovascular Prevention \& Rehabilitation, 5, 313-318. doi:10.1177/174182679800500505

[22] Komatsu, F., Kagawa, Y., Kawabata, T., Kaneko, Y. and Ishiguro, K. (2009) Relationship of dietary habits and obesity to oxidative stress in Palauan people: Compared with Japanese and Mongolian people. Current Aging Science, 2, 214-222. doi:10.2174/1874609810902030214

[23] Kjøllesdal, M.R., Holmboe-Ottesen, G. and Wandel, M. (2011) Frequent use of staff canteens is associated with unhealthy dietary habits and obesity in a Norwegian adult population. Public Health Nutrition, 14, 133-141. doi:10.1017/S1368980010001473

[24] Xie, J., Liu, L., Miao, R.J. and Zhang, X.Y. (2008) Influencing Factors to Self Rated Health States Among Students in Tianjin Medical Unversity. Chinese Journal of School Health, 29, 241-243.

[25] Zhang, L.P. (2006) Analysis of health standard grade of the colleges' present conditions in Xi'an. Journal of Xi' an Physical Education University, 23, 38-41.

[26] Sakamaki, R., Toyama, K., Amamoto, R., Liu, C.-J. and Shinfuku, N. (2005) Nutritional knowledge, food habits and health attitude of Chinese university students-A cross sectional study. Nutrition Journal, 4, 4. doi:10.1186/1475-2891-4-4

[27] Yang, G.R. (2000) National survey for college students' health condition. Chinese Journal of School Health, 23, $2-4$

[28] Zhang, Y.X. and Wang, S.R. (2010) Changes in the distribution of body mass index among college students in Shandong, China from 1985 to 2005. Anthropological Science, 118, 123-127. doi:10.1537/ase.091015 